\title{
Estudo Comparativo Entre Alvenaria Estrutural e Alvenaria de Vedação Comum
}

Thaís da Silva Pereira; Fernanda Chicoginigi Alves; Luciano Gonçalves Gomes; Marcelo Henrique Silva; Sabrina Rafaela Rosa; Sérgio Luis Fernandes Silva, Carolina Oliveira Pinto.

Universidade de Uberaba

thais_silvapereira@hotmail.com; carolina.pinto@uniube.br

\section{1 - Introdução}

Devido à alta competitividade no setor da construção civil, as empresas buscam cada vez mais métodos alternativos de construção, que diminuam o tempo de execução e também os custos da obra, sem interferir na qualidade do empreendimento, desta forma, novas tecnologias são empregadas e dentre elas a alvenaria estrutural, que está cada vez mais disseminada neste setor, principalmente nos últimos anos.

A alvenaria estrutural é uma alternativa de construção muito antiga, que surgiu diante às concepções empíricas dos povos das civilizações anteriores, sendo empregada em grandes obras existentes até os dias atuais como é o caso do Coliseu de Roma. Porém, com a revolução industrial, o uso do aço e do concreto armado foi difundido e esse antigo método foi deixado em segundo plano e a alvenaria passou a ter a finalidade apenas de vedação para as construções.

Estudos indicam que a utilização de alvenaria estrutural representa uma economia no orçamento de uma construção, em comparação a obras que utilizam estruturas de concreto armado, além de reduzir o tempo de execução, sua utilização também diminui o número de mão de obra necessária e o desperdício de materiais.

Dentre as desvantagens da utilização da alvenaria estrutural, pontuamos as fissuras que esse tipo de construção costuma apresentar e as restrições de possibilidades de mudanças não planejadas.

A seguinte pesquisa comparar a viabilidade do uso da alvenaria estrutural com a alvenaria de vedação com vigas e pilares de concreto armado, levando em conta quesitos como qualidade, custo, resistência e demais vantagens e desvantagens, bem como o detalhamento dos componentes construtivos de cada tipologia de alvenaria. Ao final, espera-se que seja possível estabelecer parâmetros de viabilidade que irão definir qual a metodologia mais vantajosa para cada construção.

\section{2 - Materiais e métodos}

Foi feita uma revisão bibliográfica, utilizando-se normas técnicas e artigos publicados entre os anos de 2004 e 2012. Essas publicações foram buscadas nas normas da ABTN e em vários bancos de dados como os repositórios de universidades e bibliotecas digitais.

\section{3 - Resultados e discussão}

As construções atuais, em sua maioria, utilizam a alvenaria comum como método construtivo, porém a alvenaria estrutural vem ganhando espaço no mercado, principalmente na construção de edifícios de médio e grande porte. A principal característica desse novo sistema é que não há pilares e vigas, sendo composta apenas de paredes que irão suportar o peso da laje ou da cobertura.

Cada tipo de alvenaria utiliza materiais de construção distintos. $\mathrm{Na}$ alvenaria convencional são utilizados os pilares e as vigas que servem como a base da estrutura. Eles são moldados por formas de madeira que são preenchidas por armaduras de aço e concreto. Posteriormente as paredes serão fechadas por blocos de vedação. Já na alvenaria estrutural são utilizados blocos industrializados, de concreto ou cerâmicos. Esses são assentados com argamassa e preenchidos com graute, que é um tipo especial de concreto indicado ao preenchimento dos vazios e ao aumento de capacidade de resistência dos blocos. Além disso, são também utilizadas armaduras que são posicionadas verticalmente nos pontos estabelecidos pelo projeto estrutural e horizontalmente nas canaletas, vergas e contravergas.

E importante ressaltar que os blocos de vedação e os blocos estruturais possuem diferentes resistências. Enquanto os primeiros possuem seus coeficientes variando de 1,5 a 3,0 $\mathrm{MPa}$, os estruturais variam de 3,0 a $6,0 \mathrm{MPa}$, de acordo com a tipologia do bloco.

Para que a alvenaria estrutural tenha um longo um ciclo de vida, é necessário evitar medidas de paredes fora do padrão dos blocos e executar a hidráulica e elétrica junto com o assentamento dos blocos para evitar cortes futuros. Deve-se ao máximo evitar cortes nos blocos, e por isso este sistema é chamado de racionalizado. A alvenaria pode ser feita de blocos de concreto estruturais ou de blocos cerâmicos estruturais. Os blocos cerâmicos possuem peso menor, o que aumenta a velocidade da execução, e também possibilitam um conforto térmico três vezes melhor do que os blocos de concreto.

www.uniube.br/entec - UNIUBE Campus Aeroporto - Uberaba/MG 
8을 EnTec - Encontro de Tecnologia da UNIUBE / 28 a 30 de outubro de 2014

Esse método de construção possui uma quantidade menor de etapas construtivas do que uma obra de alvenaria comum, principalmente pelo fato de ser um processo construtivo mais industrializado. Com menos etapas e fases construtivas, podemos nos ater mais aos detalhes de controle da qualidade e produção, fazendo com que a edificação tenha parâmetros de qualidade e desempenho superior.

Jacoby (2012) mostrou em seu estudo sobre o projeto estrutural de um edifício executado em concreto armado e em alvenaria estrutural com blocos de concreto, que a economia gerada pelo último com relação ao graute/concreto gerou uma economia em torno de $31 \%$, a utilização de aço também foi reduzida em $37 \%$, com menores quantidades de forma e escoras e mão de obra, mostrando-se desfavorável apenas na comparação da execução da alvenaria, pois os blocos de concreto elevaram o orçamento em $126 \%$. Ao final do trabalho, foi apontada uma economia de $12 \%$ a favor da alvenaria estrutural, 0 que num mercado altamente competitivo e exigente torna totalmente viável sua utilização.

A utilização da alvenaria estrutural é mais viável para obras de grande porte, ou seja, edifícios de grande escala e maior repetição, pois o uso desse método aperfeiçoa o processo de construção, tornando-o mais rápido e consequentemente mais econômico.

Vê-se assim que esse novo conceito de construção possui diversas vantagens, porém o projeto para a sua execução deve ser muito bem definido uma vez que esse método necessita de mão de obra especializada e não permite modificações futuras que não foram previstas, nem portas e janelas fora do padrão, não podendo ser utilizado em qualquer tipo de projeto, pois as possibilidades são limitadas ao padrão dos blocos.

\section{4 - Considerações finais}

Em um mercado imobiliário cada vez mais competitivo, sistemas racionais e rápidos como a alvenaria estrutural são muito bem vindos. Além de redução de custo, esse modelo aperfeiçoa e racionaliza a construção, evitando perda de material e proporcionando uma maior exatidão na execução do projeto. No entanto, é necessário que se tenha um bom projeto a fim de analisar onde esse método será utilizado para saber se suas qualidades serão melhores que 0 de uma alvenaria comum, uma vez que esse método, depois de pronto, não permite alterações não previstas em projeto.

\section{5 - Referências}

ASSOCIAÇÃO BRASILEIRA DE NORMAS TÉCINICAS. NBR 15270-1: Componentes cerâmicos: Parte 1: Blocos cerâmicos para alvenaria de vedação - Terminologia e requisitos. 1 ed. Rio de Janeiro: ABNT, 2005. 11 p.

ASSOCIAÇÃO BRASILEIRA DE NORMAS TÉCINICAS. NBR 15270-2: Componentes cerâmicos: Parte 2: Blocos cerâmicos para alvenaria estrutural - Terminologia e requisitos. 1 ed. Rio de Janeiro: ABNT, 2005. 11 p.

ASSOCIAÇÃO BRASILEIRA DE NORMAS TÉCINICAS. NBR 6136: Blocos vazados de concreto simples para alvenaria - Requisitos Terminologia e requisitos. 2 ed. Rio de Janeiro: ABNT, 2007. 9 p.

JACOBY, Pablo Cardoso. Comparação de custos de um edifício residencial executado em alvenaria estrutural e em concreto armado. 2011. 18 f. TCC (Graduação) - Curso de Engenharia Civil, Universidade do Extremo Sul Catarinense, Santa Catarina, 2012.

FERNANDES, Marcos Joaquim Gonçalves. Estudo comparativo do uso da alvenaria estrutural com bloco de concreto simples em relação ao sistema estrutural em concreto armado. 2010. $18 \mathrm{f}$. TCC (Graduação) - Curso de Engenharia Civil, Universidade Católica do Salvador, Salvador, 2010.

GUILHERME, Alexandre E.S.; ROCHA, Elton Alean. Patologias em Alvenaria Estrutural de Blocos Cerâmicos. 2012. Trabalho de Conclusão de Curso Tecnologia do Concreto- Universidade Tecnológica Federal do Paraná. Curitiba, 2012

MORAIS, António. Alvenaria Estrutural: Novo Processo Construtivo. 2006. 11 f. Dissertação (Mestrado) - Curso de Arquitetura, Faculdade de Arquitectura UT Lisboa, Lisboa, 2006.

\section{Agradecimentos}

À Universidade de Uberaba e à professora Carolina Pinto pela orientação que nos foi fornecida. 